\title{
A comparative study for the agricultural tractor selection problem
}

\author{
Ayşegül Tuş Işsk* and Esra Aytaç Adalı
}

Department of Business Administration, Pamukkale University, 20070, Denizli, Turkey

\section{H R O N I C L E}

Article history:

Received February 25, 2016

Received in revised format:

February 28, 2016

Accepted March 15, 2016

Available online

March 162016

Keywords:

COPRAS

EVAMIX

Borda

Copeland

\begin{abstract}
A B S T R A C T
Agricultural tractor selection is vital for farms, farmers or other agricultural companies in terms of success and competitiveness in the global market. This selection may be assumed as a MCDM (Multi Criteria Decision Making) problem involving qualitative and quantitative factors that must be simultaneously integrated into the selection process. At the same time there are many agricultural tractor alternatives in the market when purchasing an agricultural tractor. This paper deals with the agricultural tractor selection problem using TOPSIS method. This problem is also solved with two other MCDM methods; COPRAS (COmplex PRoportional ASsessment) and EVAMIX (EVAluation of MIXed Data) to rank the tractors alternatives. Lastly Borda and Copeland methods are used to aggregate all three ranking results.
\end{abstract}

(C) 2016 Growing Science Ltd. All rights reserved.

\section{Introduction}

Agricultural productions such as vegetables, animals, fisheries, microorganisms and energies are prepared using agricultural inputs such as soil, water and biological sources. The use of modern agricultural machines instead of primitive tools, machinery, equipment and facilities is called agricultural mechanization. Agricultural mechanization is generally used for increasing productivity of land and labor (Akdemir, 2013). According to Akdemir (2013) main agricultural mechanization problems are small scale and fragmented farming, unnecessary tractor and agricultural machinery selection, lack of knowledge on effective and proper usage, maintenance of tractor and agricultural machineries and old combined tractor park. In this study it is focused on the agricultural machinery selection which is the important part of the machinery management decision. Among the agricultural machines, tractors are handled. Tractor is one of the most important tools on acreage and plays an important role in agricultural production. The purchase of a tractor and associated equipment need substantial investment. The result of improper tractor selection can be costly. For example when a relatively small tractor is chosen for a large land, it's faced with long hours in the field, excessive delays and premature replacement whereas a relatively big tractor can result in excessive operating and

\footnotetext{
* Corresponding author. Tel: +9025829626 97, Fax: +902582962626

E-mail address: atus@pamukkale.edu.tr (A. T. Işık)

(C) 2016 Growing Science Ltd. All rights reserved. doi: $10.5267 /$ j.dsl.2016.3.002
} 
overhead costs (Sumner \& Williams, 2007). So it can be said that the selection of tractor is a complex problem in machinery management because of the wide range of machinery types, different available sizes, capital investment, competent technician labor requirement, timeliness, types of crops, unbalanced crop rotation and other related factors (Osman, 2011). Farmers, farms or decision makers have to consider different methods which incorporate the conflicting criteria in order to identify the best alternative. In the literature, this selection has been made using different ways. Mehta et al. (2011) developed a Decision Support System (DSS) to select a tractor and its matching equipment for different soils and operating conditions. Zhou (2011) proposed a new comprehensive assessment method, which combines neural networks and support vector machine based on Particle Swarm Optimization (PSO). Grisso et al. (2014) used tractor test data for selecting farm tractors. García-Alcaraz et al. (2016) proposed hybrid and multi-attribute approach to assess a set of agricultural tractors based on Analytic Hierarch Process (AHP) and Technique for Order Preference by Similarity to Ideal Solution (TOPSIS) methods. Bol and Mohammed (2005) developed a mathematical model for farm machinery selection. Osman (2011) developed a model for optimization of farm machinery management by linear programming.

Differently from the other studies in the literature, COPRAS (COmplex PRoportional ASsessment) and EVAMIX (EVAluation of MIXed Data) methods are performed including the application of the tractor selection problem in this paper. The illustrative example related with the tractor selection problem is taken from Garcia-Alacaz et al. (2016) who used TOPSIS method before. Then the ranking orders of COPRAS, EVAMIX and TOPSIS methods are aggregated by Borda and Copeland methods. According to these methods the best ranking of alternatives is defined. The novelty of this paper is to solve the agricultural tractor selection problem with COPRAS and EVAMIX methods against the existing TOPSIS method and aggregating these three methods with Borda method and Copeland methods.

The rest of this paper is organized as follow. General information about the COPRAS and EVAMIX methods are given in Section 2 and Section 3, respectively. Borda and Copeland methods that are the MCDM aggregation methods are explained in Section 4. Section 5 is provided for the agricultural tractor selection problem. Lastly in Section 6 the results of the application are presented and recommendations for future studies are discussed.

\section{COPRAS Method}

The COPRAS (COmplex PRoportional ASsessment) method was first introduced by Zavadskas et al. (1994). This method compares the alternatives and determines their priorities under the conflicting criteria by taking into account the criteria weights (Zavadskas et al., 2009). It assumes direct and proportional dependences of the significance and utility degree (priority) of the alternatives. Selection of the best alternative is made by considering both the ideal and the ideal-worst solutions (Chatterjee $\&$ Chakraborty, 2014). In the literature, there are many applications of COPRAS method. Zavadskas et al. (2001) proposed COPRAS method for assessing building life cycles to select the best alternative. Vilutienè and Zavadskas (2003) determined the effective variant of a dwelling maintenance work and performance with this method. Zavadskas et al. (2004) used COPRAS method for developing a housing credit access model. Zavadskas and Vilutiene (2004) determined the appropriate maintenance contractors for apartment blocks. Kaklauskas et al. (2005) proposed COPRAS method for designing and refurbishment of building. Andruškevicius (2005) used this method for selecting the best contractor for the construction of a trade and entertainment center. Kaklauskas et al. (2006) evaluated contractors for the replacement of windows in Vilnius Gediminas Technical University main building. Kaklauskas et al. (2007a) selected the best construction alternative with COPRAS method. Kaklauskas et al. (2007b) determined the market value of real estate with help of COPRAS method. Zavadskas et al. (2007) proposed to use COPRAS method for evaluating road design alternatives. Viteikiene and Zavadskas (2007) used COPRAS method for evaluating the sustainability of residential areas in Vilnius City. Zagorskas et al. (2007) determined sustainable city compactness by using COPRAS method. 
Banaitiene et al. (2008) used COPRAS method to select a building's life cycle. Kaklauskas et al. (2010) evaluated intelligent built environment alternatives in industrialized countries. Kanapeckiene et al. (2010) proposed Knowledge Based Decision Support System for Construction Projects Management (KDSS-CPM) to select a land parcel from the alternatives. Das et al. (2012) applied COPRAS method to measure relative performance of Indian technical institutions. Mulliner et al. (2013) evaluated the affordability of different housing locations by considering economic, environmental and social criteria. Chatterjee and Chakraborty (2014) used COPRAS method to select the most appropriate Flexible Manufacturing System (FMS) for a manufacturing firm. Also COPRAS-G method was used for the selection of investment project (Popovic et al., 2012), the effective dwelling house walls (Zavadskas et al., 2008a), construction project manager (Zavadskas et al., 2008b), contractor (Zavadskas et al., 2008c), best web site (Bindu Madhuri et al., 2010) and material (Chatterjee \& Chakraborty, 2012; Maity et al., 2012).

The following steps are applied for the COPRAS method. It is assumed that there are $m$ alternatives and $n$ criteria in the problem (Chatterjee \& Chakraborty, 2014):

Step 1: The normalized decision matrix is acquired with linear normalization procedure using Eq. (1) (Kaklauskas et al., 2006):

$$
r_{i j}=\frac{x_{i j}}{\sum_{i=1}^{m} x_{i j}}, \quad(\mathrm{i}=1,2, \ldots, \mathrm{m} ; \mathrm{j}=1,2, \ldots, \mathrm{n})
$$

where $x_{i j}$ and $r_{i j}$ are the performance of the $i^{\text {th }}$ alternative with respect to the $j^{\text {th }}$ criterion and its normalized value, respectively. The values of the criteria with having different units of measurement should be normalized in order to compare them, accordingly (Zavadskas et al., 2009).

Step 2: Normalized decision making matrix $(D)$ is weighted as:

$$
\mathrm{D}=\left[\mathrm{d}_{\mathrm{ij}}\right]_{\mathrm{mxn}}=\mathrm{r}_{\mathrm{ij}} \mathrm{w}_{\mathrm{j}}
$$

where $w_{j}$ is the importance weight of $j$ th criterion.

Step 3: The weighted normalized values are summed for both beneficial and non-beneficial criteria ( $\mathrm{S}_{+\mathrm{i}}$ and $\mathrm{S}_{-\mathrm{i}}$ ).

$$
\begin{aligned}
& S_{+i}=\sum_{j=1}^{n} d_{+i j} \\
& S_{-i}=\sum_{j=1}^{n} d_{-i j}
\end{aligned}
$$

$d_{+i j}$ and $d_{-i j}$ are the weighted normalized values for the beneficial and non-beneficial criteria, respectively. The greater the value of $S_{+i}$, the better is the alternative and the lower the value of $S_{-i}$, the better is the alternative. The $S_{+i}$ and $S_{-i}$ values express the degree of goals attained by each alternative. In any case the sums of $S_{+i}$ and the sums of $S_{-i}$ are equal to the weighted sums for the beneficial and non-beneficial criteria as expressed by the following equations:

$$
\begin{aligned}
& \sum_{\mathrm{i}=1}^{\mathrm{m}} \mathrm{S}_{+\mathrm{i}}=\sum_{\mathrm{i}=1}^{\mathrm{m}} \sum_{\mathrm{j}=1}^{\mathrm{n}} \mathrm{d}_{+\mathrm{ij}} \\
& \sum_{\mathrm{i}=1}^{\mathrm{m}} \mathrm{S}_{-\mathrm{i}}=\sum_{\mathrm{i}=1}^{\mathrm{m}} \sum_{\mathrm{j}=1}^{\mathrm{n}} \mathrm{d}_{-\mathrm{ij}}
\end{aligned}
$$

Step 4: The relative significances or priorities of each alternative $\left(Q_{i}\right)$ are determined using the following formula: 


$$
Q_{i}=S_{+i}+\frac{S_{-\min } \sum_{i=1}^{m} S_{-i}}{S_{-i} \sum_{i=1}^{m}\left(S_{-\min } / S_{-i}\right)}=S_{+i}+\frac{\sum_{i=1}^{m} S_{-i}}{S_{-i} \sum_{i=1}^{m}\left(1 / S_{-i}\right)} \theta,
$$

where $S_{-\min }$ is the minimum value of $S_{-i}$. The greater the value of $Q_{i}$, the higher is the priority of the alternative. The relative significance value of an alternative shows the degree of satisfaction attained by that alternative. The alternative with the highest relative significance value $\left(Q_{\max }\right)$ is the best choice among the alternatives.

Step 5: The quantitative utility for each alternative $\left(U_{i}\right)$ is calculated. The degree of an alternative's utility which leads to a complete ranking of the alternatives is determined by comparing the priorities of all the alternatives with the most efficient one and can be denoted as below:

$$
U_{i}=\left[\frac{Q_{i}}{Q_{\max }}\right] .100 \%
$$

where $Q_{\max }$ is the maximum relative significance value. These utility values of the alternatives range from $0 \%$ to $100 \%$.

\section{EVAMIX Method}

The EVAMIX (EVAluation of MIXed Data) method was first introduced by Voogd (1982, 1983) and then developed by Nijkamp et al. (1990), Martel and Matarazzo (2005). EVAMIX is a MCDM method that combines both ordinal (qualitative) and cardinal (quantitative) criteria within the same evaluation matrix. It is especially designed to deal with the mixed data. In other words, EVAMIX method makes different computations to the data in the evaluation matrix depending on whether it is ordinal or cardinal (Hajkowicz \& Higgins, 2008). This characteristic is the main difference between EVAMIX and other MCDM methods (Chatterjee et al., 2011). EVAMIX is a simple decision support tool basically it requires pairwise comparison of alternatives. For each pair of alternatives, a dominance score for the ordinal and cardinal criteria are calculated. Then these dominance scores are combined into an overall dominance score of each alternative (Hinloopen et al., 2004). Ranking of alternative is obtained according to the appraisal scores (Chatterjee \& Chakraborty, 2013).

In the literature, there are many applications of EVAMIX method. Qureshi et al. (1999) presented environmental and natural resource management model using weighted summation, expected value and EVAMIX. Maimone (2001) used EVAMIX method for ranking water resources projects in terms of organizing water resource and prioritizing watersheds for implementation of watershed restoration measures and spill sites for cleanup by a major electric power utility in Pennsylvania. Hajkowicz and Higgins (2008) solved six water management decision problems with weighted summation, range of value, PROMETHEE II, EVAMIX and compromise programming. Their results showed that different MCDM methods were in strong agreement with high correlations amongst rankings. Chung and Lee (2009) proposed potential flood damage, potential streamflow depletion, potential water quality deterioration and watershed evaluation index to identify the spatial ranking of hydrological vulnerability to the Korean urban watershed. Each index was calculated using composite programming, compromise programming, ELECTRE II, Region method and EVAMIX method. Chatterjee et al. (2011) illustrated two examples of COPRAS and EVAMIX methods while solving complex material selection decision making problems involving ordinal and cardinal criteria. Dosal et al. (2012) developed a methodology based on EVAMIX, weighted Summation, ELECTRE II and Regime for selecting optimal location of C\&DW recycling facilities in Cantabria, a northern Spanish region. Chatterjee and Chakraborty (2013) applied EVAMIX method for solving the nontraditional machining process selection problems in order to show details the applicability, suitability and potentiality of the method. Cerreta and Malangone (2013) identified alternative strategies of transformation for Amalfi and the Valle dei Mulini then assessed applying respectively the EVAMIX 
and ANP methods. Darji and Rao (2013) combined EVAMIX method with AHP for selection of right material. Chatterjee and Chakraborty (2014) presented the application of six MCDM methods for selecting the best flexible manufacturing system for a given manufacturing organization. Ebrahim and Abolfazl (2014) used AHP and EVAMIX models for ranking of seven flood management measures in Gorganrood River flood management project. Sohrabi and Nemati (2015) used EVAMIX for ranking of the five anti-corruption approaches under seven criteria.

The following steps are applied for the EVAMIX method (Hajkowicz and Higgins, 2008; Chatterjee and Chakraborty, 2013; 2014):

Step 1: First, criteria are divided into two categories as the ordinal and cardinal.

Step 2: The original data is normalized using linear normalization procedure. Eq. (9) and Eq. (10) are performed for the beneficial and non-beneficial criteria respectively:

$$
\begin{aligned}
& r_{i j}=\frac{x_{i j}-\min \left(x_{i j}\right)}{\max \left(x_{i j}\right)-\min \left(x_{i j}\right)}, \quad i=1, \cdots, m \text { and } j=1, \cdots, n \\
& r_{i j}=\frac{\max \left(x_{i j}\right)-x_{i j}}{\max \left(x_{i j}\right)-\min \left(x_{i j}\right)} \quad i=1, \cdots, m \text { and } j=1, \cdots, n
\end{aligned}
$$

Step 3: Unique pairs of alternatives are identified and dominance scores of $i$ th alternative on each ordinal and cardinal criterion with respect to other alternatives are calculated. Then Eq. (11) and Eq. (13) are performed for computing the dominance scores of each alternative pair $\left(\mathrm{i}, \mathrm{i}^{\prime}\right)$ for all the ordinal and cardinal criteria respectively:

$$
\begin{aligned}
& \alpha_{i i^{\prime}}=\left[\sum_{j \in O}\left\{w_{j} \operatorname{sgn}\left(r_{i j}-r_{i^{\prime} j}\right)\right\}^{c}\right]^{1 / c} \\
& \operatorname{sgn}\left(r_{i j}-r_{i^{\prime} j}\right)=\left\{\begin{array}{ccc}
+1 & \text { if } \quad r_{i j}>r_{i^{\prime} j} \\
0 & \text { if } \quad r_{i j}=r_{i^{\prime} j} \\
-1 & \text { if } \quad r_{i j}<r_{i^{\prime} j}
\end{array}\right. \\
& \gamma_{i i^{\prime}}=\left[\sum_{j \in C}\left\{w_{j}\left(r_{i j}-r_{i^{\prime} j}\right)\right\}^{c}\right]^{1 / c} \quad c=1,3,5, \ldots
\end{aligned}
$$

In these formulas $\alpha_{\mathrm{ii}^{\prime}}$ and $\gamma_{\mathrm{ii}^{\prime}}$ are ordinal and cardinal dominance scores, respectively. $O$ and $C$ are the sets of ordinal and cardinal criteria. $w_{j}$ is the weight of $j$ th criterion. The weights can be found by any weighting techniques. $c$ is a scaling parameter which controls the influences of differences arising from minor criteria. The larger $c$ is the lesser the influences of differences on minor criteria.

Step 4: The standardized dominance scores are calculated because of the different units of the ordinal and cardinal dominance scores. In the literature there many approaches to derive standardized dominance scores. In this paper an additive interval method is performed for standardized ordinal dominance score $\left(\delta_{\mathrm{ii}^{\prime}}\right)$ and standardized cardinal dominance score $\left(\mathrm{d}_{\mathrm{ii}^{\prime}}\right)$ as follows:

$$
\begin{array}{r}
\delta_{\mathrm{ii}^{\prime}}=\frac{\alpha_{\mathrm{ii}^{\prime}}-\alpha^{-}}{\alpha^{+}-\alpha^{-}} \\
\mathrm{d}_{\mathrm{ii}^{\prime}}=\frac{\gamma_{\mathrm{ii}^{\prime}}-\gamma^{-}}{\gamma^{+}-\gamma^{-}}
\end{array}
$$


$\alpha^{+}$and $\alpha^{-}$are the highest and lowest ordinal dominance score for the alternative pair $\left(i, i^{\prime}\right) . \gamma^{+}$and $\gamma^{-}$are the highest and lowest cardinal dominance score for the alternative pair $\left(\mathrm{i}, \mathrm{i}^{\prime}\right)$.

Step 5: The overall dominance score $\left(\mathrm{D}_{\mathrm{ii}^{\prime}}\right)$ is calculated for each pair of alternatives as follows:

$$
\mathrm{D}_{\mathrm{ii}}=\mathrm{w}_{\mathrm{O}} \delta_{\mathrm{ii}^{\prime}}+\mathrm{w}_{\mathrm{C}} \mathrm{d}_{\mathrm{ii}^{\prime}}
$$

$w_{o}$ is the sum of weights assigned to the ordinal criteria $\left(\mathrm{w}_{\mathrm{O}}=\sum_{\mathrm{j} \in \mathrm{O}} \mathrm{w}_{\mathrm{j}}\right)$ and $w_{C}$ is the sum of weights assigned to the cardinal criteria $\left(\mathrm{w}_{\mathrm{C}}=\sum_{\mathrm{j} \in \mathrm{C}} \mathrm{w}_{\mathrm{j}}\right)$.

Step 6: Finally the appraisal score for each alternative $\left(\mathrm{S}_{\mathrm{i}}\right)$ is computed as follows:

$$
\mathrm{S}_{\mathrm{i}}=\left(\sum_{\mathrm{i}^{\prime}} \frac{\mathrm{D}_{\mathrm{i}^{\prime} \mathrm{i}}}{\mathrm{D}_{\mathrm{ii}^{\prime}}}\right)^{-1}
$$

As seen Eq. (17) the appraisal score of each alternative depends on the overall dominance score of it. The appraisal score for each alternative is used to determine the final ranking of alternatives from best to worst. Higher appraisal score means better performance of the alternative.

\section{Aggregation methods}

MCDM methods find a set of ranking orders of alternatives. The results of different methods may not be same because of the different conceptual assumptions of the methods. In this manner aggregation of the methods may be needed. In this paper the Borda and Copeland methods are used for performing the aggregation.

\subsection{Borda Method}

The Borda method is based on the concept of voting and a majority rule binary relation (Hwang and Yoon, 1981). This method allows a voter to rank a set of alternatives by assigning different preferences to each alternative (Saari, 1995). For each method it compares each pair of alternatives $\left(A_{i}, A_{i^{\prime}}\right)$ separately and then an $\mathrm{N} \times \mathrm{N}$ matrix is formed. For each pair of alternatives the number of votes is defined as the number of "supporting" methods in which $A_{i}$ is more preferable than $A_{i^{\prime}}$. In NxN matrix $\mathrm{X}, \quad \mathrm{x}_{\mathrm{ii}}$, takes the value of 1 if $\mathrm{A}_{\mathrm{i}}$ receives more votes than $\mathrm{A}_{\mathrm{i}^{\prime}}$ and 0 , otherwise. At the same time $\mathrm{x}_{\mathrm{ii}}$ and $x_{i^{\prime} i}$ are both 0 if $A_{i}$ and $A_{i^{\prime}}$ take the same number of votes. For this matrix, the numbers in each row is summed and denoted by $S_{j}$. $S_{j}$ indicates the number of "wins" that $A_{i}$ has received against other alternatives. Hence the alternative with the highest $S_{j}$ is considered the most preferable (Cheng, 2000).

\subsection{Copeland Method}

The Copeland is another method that is based on a voting concept. This method is an extension of the Borda method and the modification of the majority rule case taking into account "losses" as well as "wins" (Hwang and Yoon, 1981). It starts with the end of Borda method. The number of "losses" $\left(S_{j^{\prime}}\right)$ is calculated by summing the values of each column of the matrix. Then the Copeland score of all alternatives are obtained by subtracting the number of "losses" $\left(S_{j^{\prime}}\right)$ from the number of "wins" $\left(S_{j}\right)$ (Pourjavad and Shirouyehzad, 2011). The Copeland method ranks the alternatives in descending order as Borda method does.

\section{Application}

In this section, the applicability of MCDM demonstrated with the implementation in a real life case taken from Garcia-Alacaz et al. (2016). The problem is the selection of the best tractor. This selection 
problem includes six criteria as initial cost of the tractor (IC), rated power (RP), number of cylinders (NC), displacement (DI), safety of the operator when maneuvering the tractor (SO) and after-sale customer service from suppliers (CS). The first four criteria are quantitative and can be expressed by certain measurement. The last two criteria are qualitative. In the problem there are seven tractor alternatives $\left(A_{1}, A_{2}, \ldots, A_{6}\right)$. Garcia-Alacaz et al. (2016) solved this problem with TOPSIS method and found the ranking of the alternatives as $A_{5}>A_{2}>A_{6}>A_{4}>A_{3}>A_{1}$.

Differently from Garcia-Alacaz et al. (2016) same selection problem is solved by COPRAS and EVAMIX methods respectively in this paper. Then Borda and Copeland methods are applied in order to aggregate the ranking of the alternatives that is found from these three MCDM methods. Application section begins with forming of the decision matrix shown in Table 1. In this table necessary data for performance evaluation of alternatives are summarized. Among these six criteria SO, CS and RP are beneficial where higher values are desirable; IC, NC and DI are non-beneficial where smaller values are desirable. Beneficial criteria are maximized whereas non-beneficial criteria are minimized. GarciaAlacaz et al. (2016) employed the AHP method to determine the weights of considered criteria. These weights are $\mathrm{wSO}_{\mathrm{SO}}=0,07696, \mathrm{w}_{\mathrm{CS}}=0,37834, \mathrm{w}_{\mathrm{IC}}=0,23857, \mathrm{w}_{\mathrm{RP}}=0,08151, \mathrm{w}_{\mathrm{NC}}=0,10869$ and $\mathrm{w}_{\mathrm{DI}}=$ 0,11593 .

Table 1

Decision matrix

\begin{tabular}{ccccccc}
\hline & SO & CS & IC & RP & NC & DI \\
\hline $\mathrm{A}_{1}$ & 8,8 & 8,6 & 748223,0 & 80,0 & 4,0 & 4530,0 \\
$\mathrm{~A}_{2}$ & 7,3 & 7,3 & 520730,0 & 75,0 & 4,0 & 4500,0 \\
$\mathrm{~A}_{3}$ & 6,2 & 5,3 & 425232,5 & 80,0 & 4,0 & 4070,0 \\
$\mathrm{~A}_{4}$ & 7,3 & 6,2 & 649477,5 & 100,0 & 6,0 & 6000,0 \\
$\mathrm{~A}_{5}$ & 8,2 & 8,3 & 585305,0 & 95,0 & 4,0 & 4000,0 \\
$\mathrm{~A}_{6}$ & 8,6 & 8,5 & 702590,0 & 110,0 & 6,0 & 6000,0 \\
\hline Criteria type & Max & Max & Min & Max & Min & Min \\
\hline
\end{tabular}

\subsection{Application of COPRAS Method}

The first step of COPRAS method is the normalization of the decision matrix so the decision matrix is normalized using Eq. (1) as seen in Table 2. Then, the corresponding weighted normalized decision matrix is developed using Eq. (2) as given in Table 3.

Table 2

Normalized decision matrix

\begin{tabular}{ccccccc}
\hline & SO & CS & IC & RP & NC & DI \\
\hline $\mathrm{A}_{1}$ & 0,1897 & 0,1946 & 0,1481 & 0,2060 & 0,1429 & 0,1557 \\
$\mathrm{~A}_{2}$ & 0,1573 & 0,1652 & 0,1389 & 0,1434 & 0,1429 & 0,1546 \\
$\mathrm{~A}_{3}$ & 0,1336 & 0,1199 & 0,1481 & 0,1171 & 0,1429 & 0,1399 \\
$\mathrm{~A}_{4}$ & 0,1573 & 0,1403 & 0,1852 & 0,1788 & 0,2143 & 0,2062 \\
$\mathrm{~A}_{5}$ & 0,1767 & 0,1878 & 0,1759 & 0,1612 & 0,1429 & 0,1375 \\
$\mathrm{~A}_{6}$ & 0,1853 & 0,1923 & 0,2037 & 0,1935 & 0,2143 & 0,2062 \\
\hline
\end{tabular}

Table 3

Weighted normalized decision matrix

\begin{tabular}{lllllll}
\hline & $\mathrm{SO}$ & $\mathrm{CS}$ & $\mathrm{IC}$ & $\mathrm{RP}$ & $\mathrm{NC}$ & $\mathrm{DI}$ \\
\hline $\mathrm{A}_{1}$ & 0,0146 & 0,0736 & 0,0121 & 0,0492 & 0,0155 & 0,0180 \\
$\mathrm{~A}_{2}$ & 0,0121 & 0,0625 & 0,0113 & 0,0342 & 0,0155 & 0,0179 \\
$\mathrm{~A}_{3}$ & 0,0103 & 0,0454 & 0,0121 & 0,0279 & 0,0155 & 0,0162 \\
$\mathrm{~A}_{4}$ & 0,0121 & 0,0531 & 0,0151 & 0,0427 & 0,0233 & 0,0239 \\
$\mathrm{~A}_{5}$ & 0,0136 & 0,0710 & 0,0143 & 0,0385 & 0,0155 & 0,0159 \\
$\mathrm{~A}_{6}$ & 0,0143 & 0,0728 & 0,0166 & 0,0462 & 0,0233 & 0,0239 \\
\hline
\end{tabular}


Based on Eq. (3) and Eq. (4), the sums of the weighted normalized values are calculated for both the beneficial criteria $\left(S_{+i}\right)$ and non-beneficial criteria $\left(S_{-i}\right)$, as shown in Table 4 . Then, applying Eq. (7) and Eq. (8), the relative significance or priority value $\left(Q_{i}\right)$ and the quantitative utility $\left(U_{i}\right)$ for each alternative are computed, as given in Table 5. According to the calculation results, the complete ranking of the alternatives is obtained as $A_{5}>A_{2}>A_{1}>A_{6}>A_{3}>A_{4} . A_{5}$ is the best alternative with $100 \%$ utility degree.

\section{Table 4}

$S_{+i}$ and $S_{-i}$ values

\begin{tabular}{llllll}
\hline & $\mathrm{S}_{+\mathrm{i}}$ & $\mathrm{S}_{-\mathrm{i}}$ & & $\mathrm{S}_{+\mathrm{i}}$ & $\mathrm{S}_{-\mathrm{i}}$ \\
\hline $\mathrm{A}_{1}$ & 0,1003 & 0,0827 & $\mathrm{~A}_{4}$ & 0,0803 & 0,0899 \\
$\mathrm{~A}_{2}$ & 0,0859 & 0,0677 & $\mathrm{~A}_{5}$ & 0,0990 & 0,0699 \\
$\mathrm{~A}_{3}$ & 0,0677 & 0,0597 & $\mathrm{~A}_{6}$ & 0,1036 & 0,0933 \\
\hline
\end{tabular}

Table 5

$Q i$ and $U i$ values

\begin{tabular}{llllllll}
\hline & $\mathrm{Q}_{\mathrm{i}}$ & $\mathrm{U}_{\mathrm{i}}$ & $\mathrm{Rank}$ & & $\mathrm{Q}_{\mathrm{i}}$ & $\mathrm{U}_{\mathrm{i}}$ & Rank \\
\hline $\mathrm{A}_{1}$ & 0,1705 & 93,6465 & 3 & $\mathrm{~A}_{4}$ & 0,1449 & 79,5926 & 6 \\
$\mathrm{~A}_{2}$ & 0,1717 & 94,3369 & 2 & $\mathrm{~A}_{5}$ & 0,1820 & 100,0000 & 1 \\
$\mathrm{~A}_{3}$ & 0,1650 & 90,6542 & 5 & $\mathrm{~A}_{6}$ & 0,1658 & 91,0942 & 4 \\
\hline
\end{tabular}

\subsection{Application of EVAMIX Method}

EVAMIX application begins with the separation of the criteria as ordinal and cardinal. As stated previously SO and CS are ordinal whereas IC, RP, NC and DI are cardinal criteria. Then the normalized decision matrix is obtained using Eq. (9) and Eq. (10) and shown in Table 6.

Table 6

Normalized decision matrix

\begin{tabular}{ccccccc}
\hline & SO & CS & IC & RP & NC & DI \\
\hline $\mathrm{A}_{1}$ & 1,000 & 1,000 & 0,000 & 0,143 & 1,000 & 0,735 \\
$\mathrm{~A}_{2}$ & 0,423 & 0,606 & 0,704 & 0,000 & 1,000 & 0,750 \\
$\mathrm{~A}_{3}$ & 0,000 & 0,000 & 1,000 & 0,143 & 1,000 & 0,965 \\
$\mathrm{~A}_{4}$ & 0,423 & 0,273 & 0,306 & 0,714 & 0,000 & 0,000 \\
$\mathrm{~A}_{5}$ & 0,769 & 0,909 & 0,504 & 0,571 & 1,000 & 1,000 \\
$\mathrm{~A}_{6}$ & 0,923 & 0,970 & 0,141 & 1,000 & 0,000 & 0,000 \\
\hline
\end{tabular}

The dominance scores of each pair of tractors are computed and given in Table 7. "c" value is taken as 1 while applying Eq. (11) and Eq. (13). The standardized dominance scores and the overall dominance scores for all the pairs of tractors for both the ordinal and cardinal criteria are computed and shown in Table 8 and 9 , respectively.

\section{Table 7}

The dominance scores of each pair of tractors

\begin{tabular}{lcccccccc}
\hline $\begin{array}{l}\text { Tractor } \\
\text { pair }\end{array}$ & $\alpha_{\mathrm{ii}^{\prime}}$ & $\gamma_{\mathrm{ii}^{\prime}}$ & Tractor pair & $\alpha_{\mathrm{ii}^{\prime}}$ & $\gamma_{\mathrm{ii}^{\prime}}$ & Tractor pair & $\alpha_{\mathrm{ii}^{\prime}}$ & $\gamma_{\mathrm{ii}^{\prime}}$ \\
\hline$(1,2)$ & 0,4553 & $-0,1581$ & $(3,1)$ & $-0,4553$ & 0,2652 & $(5,1)$ & $-0,4553$ & 0,1860 \\
$(1,3)$ & 0,4553 & $-0,2652$ & $(3,2)$ & $-0,4553$ & 0,1071 & $(5,2)$ & 0,4553 & 0,0279 \\
$(1,4)$ & 0,4553 & 0,0744 & $(3,4)$ & $-0,4553$ & 0,3396 & $(5,3)$ & 0,4553 & $-0,0792$ \\
$(1,5)$ & 0,4553 & $-0,1860$ & $(3,5)$ & $-0,4553$ & 0,0792 & $(5,4)$ & 0,4553 & 0,2604 \\
$(1,6)$ & 0,4553 & 0,0903 & $(3,6)$ & $-0,4553$ & 0,3556 & $(5,6)$ & $-0,4553$ & 0,2763 \\
$(2,1)$ & $-0,4553$ & 0,1581 & $(4,1)$ & $-0,4553$ & $-0,0744$ & $(6,1)$ & $-0,4553$ & $-0,0903$ \\
$(2,3)$ & 0,4553 & $-0,1071$ & $(4,2)$ & $-0,3783$ & $-0,2325$ & $(6,2)$ & 0,4553 & $-0,2485$ \\
$(2,4)$ & 0,3783 & 0,2325 & $(4,3)$ & 0,4553 & $-0,3396$ & $(6,3)$ & 0,4553 & $-0,3556$ \\
$(2,5)$ & $-0,4553$ & $-0,0279$ & $(4,5)$ & $-0,4553$ & $-0,2604$ & $(6,4)$ & 0,4553 & $-0,0159$ \\
$(2,6)$ & $-0,4553$ & 0,2485 & $(4,6)$ & $-0,4553$ & 0,0159 & $(6,5)$ & 0,4553 & $-0,2763$ \\
\hline
\end{tabular}


Table 8

The standardized dominance scores

\begin{tabular}{cllllllll}
\hline $\begin{array}{l}\text { Tractor } \\
\text { pair }\end{array}$ & $\delta_{\mathrm{ii}^{\prime}}$ & $\mathrm{d}_{\mathrm{ii}^{\prime}}$ & $\begin{array}{l}\text { Tractor } \\
\text { pair }\end{array}$ & $\delta_{\mathrm{ii}^{\prime}}$ & $\mathrm{d}_{\mathrm{ii}^{\prime}}$ & $\begin{array}{l}\text { Tractor } \\
\text { pair }\end{array}$ & $\delta_{\mathrm{ii}^{\prime}}$ & $\mathrm{d}_{\mathrm{ii}^{\prime}}$ \\
\hline$(1,2)$ & 1 & 0,2776 & $(3,1)$ & 0 & 0,8730 & $(5,1)$ & 0 & 0,7615 \\
$(1,3)$ & 1 & 0,1270 & $(3,2)$ & 0 & 0,6506 & $(5,2)$ & 1 & 0,5392 \\
$(1,4)$ & 1 & 0,6046 & $(3,4)$ & 0 & 0,9776 & $(5,3)$ & 1 & 0,3886 \\
$(1,5)$ & 1 & 0,2385 & $(3,5)$ & 0 & 0,6114 & $(5,4)$ & 1 & 0,8661 \\
$(1,6)$ & 1 & 0,6270 & $(3,6)$ & 0 & 1,0000 & $(5,6)$ & 0 & 0,8886 \\
$(2,1)$ & 0 & 0,7224 & $(4,1)$ & 0 & 0,3954 & $(6,1)$ & 0 & 0,3730 \\
$(2,3)$ & 1 & 0,3494 & $(4,2)$ & 0,0845 & 0,1730 & $(6,2)$ & 1 & 0,1506 \\
$(2,4)$ & 0,9155 & 0,8270 & $(4,3)$ & 1 & 0,0224 & $(6,3)$ & 1 & 0,0000 \\
$(2,5)$ & 0 & 0,4608 & $(4,5)$ & 0 & 0,1339 & $(6,4)$ & 1 & 0,4776 \\
$(2,6)$ & 0 & 0,8494 & $(4,6)$ & 0 & 0,5224 & $(6,5)$ & 1 & 0,1114 \\
\hline
\end{tabular}

Table 9

Overall dominance scores

\begin{tabular}{llllll}
\hline Tractor pair & $\mathrm{D}_{\mathrm{ii}}$ & Tractor pair & $\mathrm{D}_{\mathrm{ii}^{\prime}}$ & Tractor pair & $\mathrm{D}_{\mathrm{ii}^{\prime}}$ \\
\hline$(1,2)$ & 0,6065 & $(3,1)$ & 0,4755 & $(5,1)$ & 0,4148 \\
$(1,3)$ & 0,5245 & $(3,2)$ & 0,3544 & $(5,2)$ & 0,7490 \\
$(1,4)$ & 0,7846 & $(3,4)$ & 0,5325 & $(5,3)$ & 0,6670 \\
$(1,5)$ & 0,5852 & $(3,5)$ & 0,3330 & $(5,4)$ & 0,9271 \\
$(1,6)$ & 0,7968 & $(3,6)$ & 0,5447 & $(5,6)$ & 0,4840 \\
$(2,1)$ & 0,3935 & $(4,1)$ & 0,2154 & $(6,1)$ & 0,2032 \\
$(2,3)$ & 0,6456 & $(4,2)$ & 0,1327 & $(6,2)$ & 0,5373 \\
$(2,4)$ & 0,8673 & $(4,3)$ & 0,4675 & $(6,3)$ & 0,4553 \\
$(2,5)$ & 0,2510 & $(4,5)$ & 0,0729 & $(6,4)$ & 0,7154 \\
$(2,6)$ & 0,4627 & $(4,6)$ & 0,2846 & $(6,5)$ & 0,5160 \\
\hline
\end{tabular}

Table 10

Appraisal scores of tractors

\begin{tabular}{ccccccc}
\hline & $\mathrm{A}_{1}$ & $\mathrm{~A}_{2}$ & $\mathrm{~A}_{3}$ & $\mathrm{~A}_{4}$ & $\mathrm{~A}_{5}$ & $\mathrm{~A}_{6}$ \\
\hline Appraisal scores & 0,3580 & 0,1565 & 0,1506 & 0,0377 & 0,2950 & 0,1367 \\
Ranking & 1 & 3 & 4 & 6 & 2 & 5 \\
\hline
\end{tabular}

The appraisal scores of alternatives are calculated and shown in Table 10. According to appraisal scores the ranking order of the tractors is obtained as $A_{1}>A_{5}>A_{2}>A_{3}>A_{6}>A_{4} . A_{1}$ and $A_{4}$ are the best and worst alternatives respectively.

\subsection{Application of Borda and Copeland methods}

Consequently the ranking results of alternatives based on the two methods are extracted in Table 5, Table 10 and TOPSIS method extracted from Garcia-Alacaz et al. (2016) are shown in Table 11 together. It can be concluded that the results of these three methods are different to each other. In this paper, Borda and Copeland methods are used to aggregate them. The aggregated results are also shown in the same table. The rank orders of the Borda and the Copeland methods are exactly the same. So, it is still possible to conclude that $A_{5}>A_{2}>A_{1}>A_{6}>A_{3}>A_{4}$ where $A_{5}$ is the most preferable. If the decision maker only looks for the most preferable solution, this conclusion is clear enough to suggest As as the best choice.

Table 11

Ranking and Aggregated Results

\begin{tabular}{llll|ll}
\hline & Ranking Results & & \multicolumn{2}{l}{ Aggregated Results } \\
\hline & COPRAS & EVAMIX & TOPSIS & Borda & Copeland \\
\hline $\mathrm{A}_{1}$ & 3 & 1 & 6 & 3 & 3 \\
$\mathrm{~A}_{2}$ & 2 & 3 & 2 & 2 & 2 \\
$\mathrm{~A}_{3}$ & 5 & 4 & 5 & 5 & 5 \\
$\mathrm{~A}_{4}$ & 6 & 6 & 4 & 6 & 6 \\
$\mathrm{~A}_{5}$ & 1 & 2 & 1 & 1 & 1 \\
$\mathrm{~A}_{6}$ & 4 & 5 & 3 & 4 & 4 \\
\hline
\end{tabular}




\section{Conclusion}

In this paper a MCDM based on COPRAS and EVAMIX methods have been applied on the tractor selection problem of Garcia-Alacaz et al. (2016). The results of two methods and TOPSIS produce different ranking of tractor alternatives. So Borda and Copeland methods are applied in order to aggregate the ranking of the alternatives. As a result of aggregation $\mathrm{A}_{5}$ and $\mathrm{A}_{4}$ are the best and worst alternatives respectively.

Both COPRAS and EVAMIX methods provide some advantages and disadvantages. Firstly COPRAS method has the potential to be popular, widely acceptable because it does not contain complex calculations and easy to apply to real life problems. Also COPRAS method is very useful when the number of alternatives and criteria are very high, because it does not need pair-wise comparison like PROMETHEE or ELECTRE methods. It can provide a complete ranking of alternatives. It can deal with both quantitative and qualitative criteria within one assessment. It has the ability to account for both positive and negative evaluation criteria, which can be assessed separately within the evaluation process. An important feature that makes the COPRAS method superior to other available MCDM methods is that it may be used to estimate the utility degree of alternatives, showing, as a percentage, the extent to which one alternative is better or worse than other alternatives taken for comparison. The main advantage of EVAMIX method is handling both ordinal and cardinal data considering all available data related to the problem. There is no need to express ordinal data quantitatively. The philosophy underlying this method is clear so decision makers may understand the application steps easily. The method is based on evaluation matrix and there is no boundary in terms of the number of criteria and alternative on this matrix. So complex decision problems can be organized and solved in a consistent manner. At the same time method is flexible because if the additional data about the problem is collected then method can be updated easily considering the new data. Solution of the problem can be executed by the help of the softwares. But this method cannot consider the interdependence between the criteria as ANP does.

In this paper efforts are devoted to show the applicability of COPRAS and EVAMIX methods for the tractor selection problem. In the future studies the same selection problem may be repeated with the new criteria and alternatives. Other MCDM methods like ELECTRE, PROMETHEE, VIKOR and MOORA may be used and the obtained results may be compared. Different selection problems include both ordinal and cardinal criteria may be handled. Different weighting methods or normalization procedures may be applied in order to find the criteria weight or normalization of performance scores of the alternatives.

\section{References}

Akdemir, B. (2013). Agricultural Mechanization in Turkey. IERI Procedia, 5, 41-44.

Andruškevicius, A. (2005). Evaluation of contractors by using COPRAS - the multiple criteria method. Technological and Economic Development of Economy, 11(3), 158-169.

Banaitiene, N., Banaitis, A., Kaklauskas, A., \& Zavadskas, E. K. (2008). Evaluating the life cycle of a building: A multivariant and multiple criteria approach. Omega, 36(3), 429-441.

Benjamin Bol, M.B. \& Mohammed, H.I. (2005). A mathematical algorithm for farm machinery selection. Journal of Science and Technology, 6 (2).

Bindu Madhuri, Ch., Chandulal. J, Padmaja. M. (2010). Selection of best web site by applying COPRASG method. International Journal of Computer Science and Information Technologies, 1(2), 138-146.

Cerreta, M., \& Malangone, V. (2013). Context aware strategies for the Valle dei Mulini of Amalfi. Sbetti F., Rossi F., Talia M., Trillo C.(a cura di), Il governo della città nella contemporaneità. La città come motore di sviluppo. Tema, 2, 57-58.

Chatterjee, P., Athawale, V. M., \& Chakraborty, S. (2011). Materials selection using complex proportional assessment and evaluation of mixed data methods. Materials \& Design, 32(2), 851-860. 
Chatterjee, P. \& Chakraborty, S. (2012). Material selection using preferential ranking methods. Materials and Design, 35, 384-393.

Chatterjee, P., \& Chakraborty, S. (2013). Nontraditional machining processes selection using evaluation of mixed data method. International Journal of Advanced Manufacturing Technology, 68, 1613-1626.

Chatterjee, P. \& Chakraborty, S. (2014). Flexible manufacturing system selection using preference ranking methods: A comparative study. International Journal of Industrial Engineering Computations, 5, 315338.

Cheng, S. K. (2000). Development of a fuzzy multi-criteria decision support system for municipal solid waste management. Regina: a thesis in graduate studies and research university of Regina.

Chung, E.S. \& Lee, K.S. (2009). Identification of spatial ranking of hydrological vulnerability using multicriteria decision making techniques: case study of Korea. Water Resour Manage, 23, 2395-2416.

Darji, V.P. \& Rao, R.V. (2013). Application of AHP/EVAMIX method for decision making in the industrial environment. American Journal of Operations Research, 3, 542-569.

Das, M.C., Sarkar, B. \& Ray, S. (2012). A framework to measure relative performance of Indian technical institutions using integrated fuzzy AHP and COPRAS methodology. Socio-Economic Planning Sciences, 46, 230-241.

Dosal, E., Coronado, M., Muñoz, I., Viguri, J.R. \& Andrés, A. (2012). Application of multi-criteria decision-making tool to locate construction and demolition waste (C\&DW) recycling facilities in a Northern Spanish Region. Environmental Engineering and Management Journal, 11(3), 545-556.

Ebrahim, B.M., \& Abolfazl, L.A. (2014). Flood management options using analytical hierarchy process and evaluation and mixed criteria. Iranian of Irrigation \& Water Engineering, 4(14) , 72-82.

García-Alcaraz, J.L., Maldonado-Macías, A.A., Hernández-Arellano, J.L., Blanco-Fernández, J., JiménezMacías, E. \& Sáenz-DíezMuro, J.C. (2016). Agricultural tractor selection: a hybrid and multi-attribute approach. Sustainability, 8(2), 157.

Grisso, R.B., Perumpral, J.V., Roberson, G.T. \& Pitman, R. (2014). Using tractor test data for selecting farm tractors. Virginia Cooperative Extension, https://pubs.ext.vt.edu/442/442-072/442-072_pdf.pdf

Hajkowicz, S., \& Higgins, A. (2008). A comparison of multiple criteria analysis techniques for water resource management. European journal of operational research, 184(1), 255-265.

Hinloopen, E., Nijkamp, P., \& Rietveld, P. (2004). Integration of ordinal and cardinal information in multicriteria ranking with imperfect compensation.European Journal of Operational Research, 158(2), 317 338.

Hwang, C.L. \& Yoon, K. (1981). Multiple Attributes Decision Making Methods and Applications, Springer, Berlin Heidelberg.

Kaklauskas, A., Zavadskas, E. K. \& Raslanas, S. (2005). Multivariant design and multiple criteria analysis of building refurbishments. Energy and Buildings, 37(4), 361-372.

Kaklauskas, A., Zavadskas, E.K., Raslanas, S., Ginevicius, R., Komka, A., \& Malinauskas, P. (2006). Selection of low e-windows in retrofit of public buildings by applying multiple criteria method COPRAS: A Lithuanian case. Energy and Buildings, 38(5), 454-462.

Kaklauskas, A., Zavadskas, E.K., \& Trinkunas, V. (2007a). A multiple criteria decision support on-line system for construction. Engineering Applications of Artificial Intelligence, 20(2), 163-175.

Kaklauskas, A., Zavadskas, E.K., Banaitis, A. \& Satkauskas. G. (2007b). Defining the utility and market value of a real estate: a multiple criteria approach. International Journal of Strategic Property Management, 11(2), 107-20.

Kaklauskas, A., Zavadskas, E. K., Naimavicienė, J., Krutinis, M., Plakys, V., \& Venskus, D. (2010). Model for a complex analysis of intelligent built environment. Automation in Construction, 19(3), 326-340.

Kanapeckiene, L., Kaklauskas, A., Zavadskas, E. K., \& Seniut, M. (2010). Integrated knowledge management model and system for construction projects. Engineering applications of artificial intelligence, 23(7), 1200-1215.

Maimone, M. (2001). Multi-criteria evaluation techniques in water resource planning. Universities Council on Water Resources in American Water Resources Association Technical Publication Series, pp. 227232;

Maity, S. R., Chatterjee, P., \& Chakraborty, S. (2012). Cutting tool material selection using grey complex proportional assessment method. Materials \& Design, 36, 372-378. 
Martel, J.M. \& Matarazzo, B. (2005). Other outranking approaches. in: Figueira J, Salvatore G, Ehrgott M. (Eds), Multiple criteria decision analysis: state of the art surveys. Springer, New York, pp. 197-262.

Mehta, C. R., Singh, K., \& Selvan, M. M. (2011). A decision support system for selection of tractorimplement system used on Indian farms. Journal of Terramechanics, 48(1), 65-73.

Mulliner, E., Smallbone, K., \& Maliene, V. (2013). An assessment of sustainable housing affordability using a multiple criteria decision making method. Omega, 41(2), 270-279.

Nijkamp, P., Rietveld, P. \& Voogd, H. (1990). Multicriteria Evaluation in Physical Planning. North Holland, Amsterdam.

Osman, N. O. A. (2011). A Model for Farm Machinery Selection. Master Thesis, University of Khartoum, Faculty of Agriculture.

Popovic, G., Stanujkic, D. \& Stojanovic, S. (2012). Investment project selection by applying Copras method and imprecise data. Serbian Journal of Management, 7(2), 257-269.

Pourjavad, E. \& Shirouyehzad, H. (2011). A MCDM approach for prioritizing production lines: a case study. International Journal of Business and Management, 6(10), 221-229

Qureshi, M. E., Harrison, S. R., \& Wegener, M. K. (1999). Validation of multicriteria analysis models. Agricultural Systems, 62(2), 105-116.

Saari, D. (1995). Basic Geometry of Voting, Berlin-Heidelberg-New York: Springer Verlag.

Sohrabi, R. \& Nemati, H. (2015). Ranking approaches to struggle corruption by using evaluation and mixed criteria (evamix). Teknologi Tanaman, 12, 370-375.

Sumner, P.E. \& Williams, E. J. (2007). What Size Farm Tractor Do I Need? Mis. Pub. No. ENG07-003, http://www.caes.uga.edu/departments/bae/extension/pubs/documents/farm\%20tractor.pdf

Vilutienè. T. \& Zavadskas, E.K. (2003). The application of multi-criteria analysis to decision support for the facility management of a residential district. Journal of Civil Engineering and Management, 9(4), 241-252.

Viteikiene, M. \& Zavadskas, E.K. (2007). Evaluating the sustainability of Vilnius city residential areas. Journal of Civil Engineering and Management, 8(2), 149-155.

Voogd, H. (1982). Multicriteria evaluation with mixed qualitative and quantitative data. Environment and Planning B: Planning and Design, 9(2), 221-236.

Voogd, H. (1983). Multicriteria Evaluation for Urban and Regional Planning. London: Pion.

Zagorskas, J., Burinskienè, M., Zavadskas, E., \& Turskis, Z. (2007a). Urbanistic assessment of city compactness on the basis of GIS applying the COPRAS method. Ekologija, 53(2), 55-63.

Zavadskas, E. K., Kaklauskas, A. \& Kvederytė, N. (2001). Multivariant design and multiple criteria analysis of building life cycle. Informatica, 12(1), 169-188.

Zavadskas, E. K., Kaklauskas, A., Banaitis, A. \& Kvederytè, N. (2004). Housing credit access model: The case for Lithuania. European Journal of Operational Research, 155(2), 335-352.

Zavadskas, E. K. \& Vilutienė T. (2004). Multi-criteria analysis of multi-family apartment blocks maintenance service packages. Journal of Civil Engineering and Management, 10(2), 143-152.

Zavadskas, E.K., Kaklauskas, A., Peldschus, F. \& Turskis Z. (2007b). Multi-attribute assessment of road design solution by using the COPRAS method. The Baltic Journal of Road and Bridge Engineering, 2(4), 195-203.

Zavadskas , E.K., Kaklauskas , A., Turskis, Z. \& Tamošaitiene, J. (2008a). Selection of the effective dwelling house walls by applying attributes values determined at intervals. Journal of Civil Engineering and Management, 14(2), 85-93.

Zavadskas, E.K., Turskis, Z., Tamosaitiene, J. \& Marina, V. (2008b). Selection of construction project managers by applying Copras-G method. The 8th International Conference "Reliability and Statistics in Transportation and Communication-2008”, 15-18 October, Riga.

Zavadskas, E.K., Kaklauskas, A., Turskis, Z. \& Tamosaitiene, J. (2008c). Contractor selection multiattribute model applying Copras method with grey interval numbers. 20th EURO Mini Conference "Continuous Optimization and Knowledge-Based Technologies", 20-23 May, 2008, Neringa.

Zavadskas, E.K., Kaklauskas, A. \& Vilutiene, T. (2009). Multicriteria evaluation of apartment blocks maintenance contractors: Lithuanian case study. International Journal of Strategic Property Management, 13(4), 319-338.

Zhou, Q., Lou, J., Xie, F. \& Liu, Q. (2011). The method research on optimum selection of agricultural machinery. International Journal of Digital Content Technology and its Applications, 5(6), 337-334. 